\title{
Early Dermoscopic Signs Leading to Primary Systemic Amyloidosis' Diagnosis: A Case Report
}

\author{
Trashita Hassanandani, Bhabani S.T.P. Singh, Bikash Ranjan Kar
}

Department of DVL, IMS \& SUM Hospital, Bhubaneswar, Odisha, India

Key words: Dermoscopy, primary systemic amyloidosis, cutaneous

Citation: Hassanandani T, Singh BSTP, Kar BR. Early Dermoscopic Signs Leading to Primary Systemic Amyloidosis' Diagnosis: A Case Report. Dermatol Pract Concept. 2021;11(3): e2021023. DOI: https://doi.org/10.5826/dpc.1103a23

Accepted: September 7, 2020; Published: July 8, 2021

Copyright: $\odot 2021$ Hassanandani et al. This is an open-access article distributed under the terms of the Creative Commons Attribution License BY-NC-4.0, which permits unrestricted noncommercial use, distribution, and reproduction in any medium, provided the original authors and source are credited.

Funding: None.

Competing interests: The authors have no conflicts of interest to disclose.

Corresponding author: Bhabani S.T.P. Singh, MBBS MD, Associate Professor, Department of DVL, IMS \& SUM Hospital, Bhubaneswar, Odisha, India. Email: drbstp@gmail.com

\section{Introduction}

Amyloidosis is characterised by an extracellular deposition of insoluble polymeric protein fibrils in tissues and organs. Skin and mucosae can be involved either as a part of primary cutaneous amyloidosis or secondary to systemic amyloidosis. Cutaneous changes are seen in about $25 \%$ of patients with primary systemic amyloidosis. Here we present unique dermoscopic features of cutaneous lesions in a case of Primary Systemic Amyloidosis (PSA).

\section{Case Presentation}

A 26-year-old male presented closely set skin-coloured papules over the eyelids, around the nose, mouth, and over the scalp. Few papules had turned red over the past 6 months (Figure 1).

The patient reported a history of generalized weakness, hoarseness of voice, and an increase in the size of his tongue (Figure 2). Dermoscopic analysis revealed lesions characterized by white to yellowish clods. Many lesions showed vascular proliferation with a glomerular pattern against a red to pink background (Figures 3 and 4).
Histopathology showed clumps of pale acellular eosinophilic material (Figure 5), positive for Congo red stain in the papillary dermis (Figure 6).

Further Investigations revealed renal impairment with proteinuria. 24-hour urine protein was $1879.8 \mathrm{mg} /$ day. Urine electrophoresis showed monoclonal spikes in the gamma region. A final diagnosis of myeloma associated systemic amyloidosis was made.

The patient started Bortezomib-Cyclophosphamide-Dexamethasone treatment cycles every 28 days and is currently under follow up.

The most common clinical cutaneous presentations of systemic amyloidosis are haemorrhagic lesions (petechiae, purpura, and ecchymoses), which are caused by amyloid deposition within dermal blood vessel walls, leading to vessel fragility. When there is a greater amount of amyloid deposition in the skin, the patient may develop papules, plaques, and even nodules, which may exhibit a haemorrhagic appearance.

In our case, the lesions were mainly translucent to skin coloured. Dermoscopic findings showed white to yellowish clods. Vascular proliferation was distinctly seen in a glomer- 


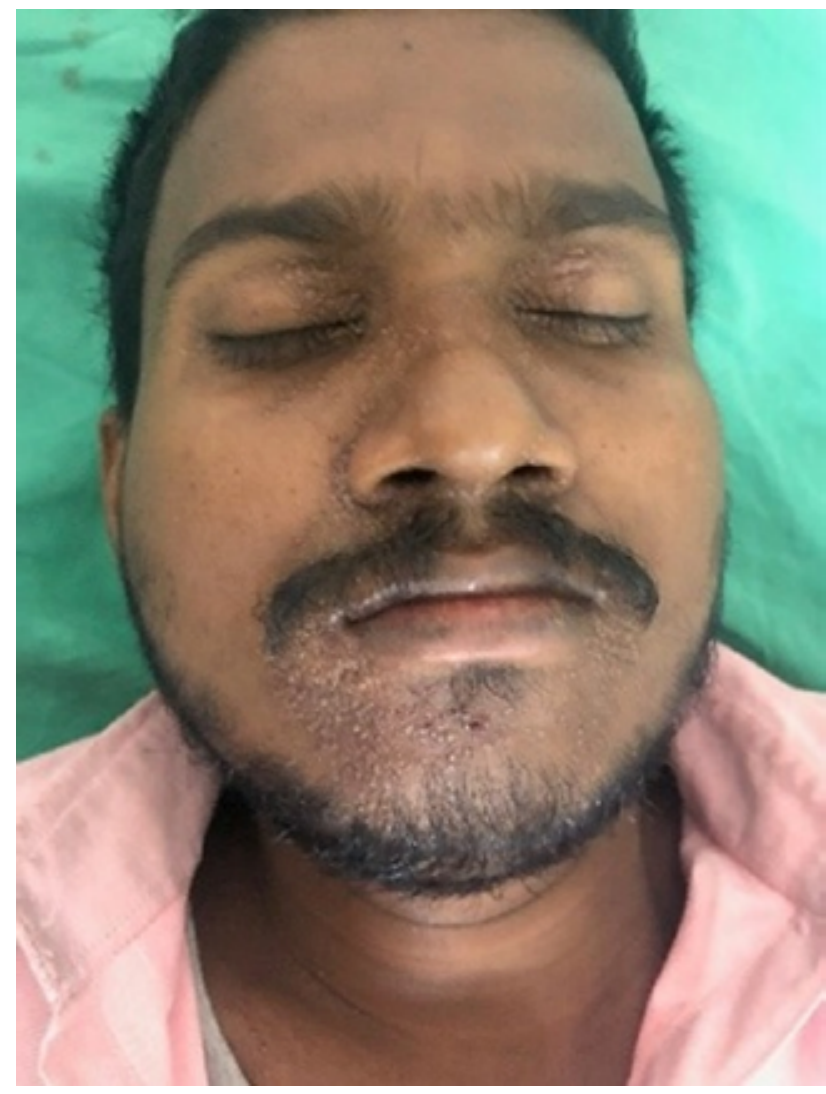

Figure 1. Skin to reddish coloured papules around the eyes, nose, and lips.

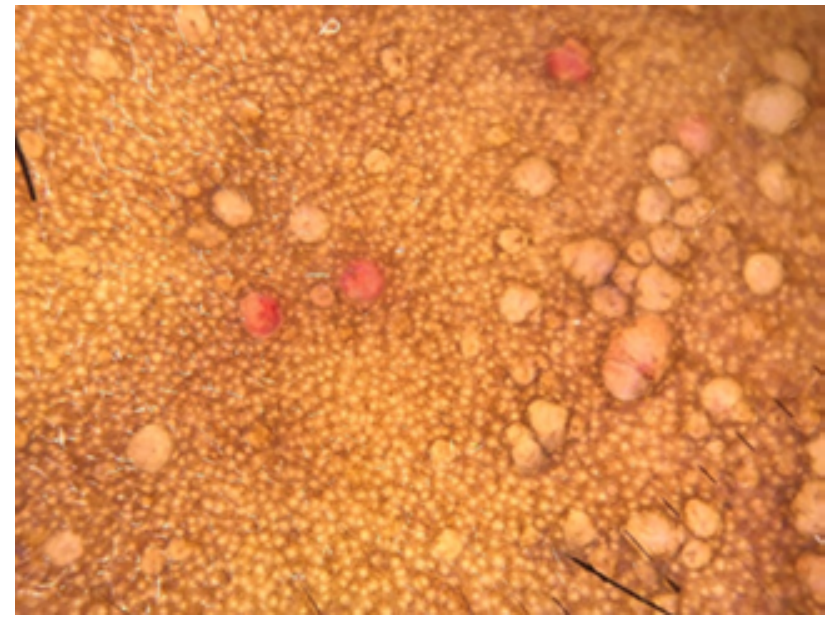

Figure 3. White to yellowish background with few lesions showing glomerular vessels (DermLite DL3, polarized view).

ular pattern with a red to pink background. The yellowish appearance of skin lesions on dermoscopic examination may correspond histologically to amyloid deposition in the upper dermis. The glomerular vessels appearing as clustered or coiled vessels located on one side of the lesion resembling renal glomeruli, correspond possibly histologically to small dermal blood vessels. A dermoscopic examination can detect early vascular changes, prior to the clinical appearance of

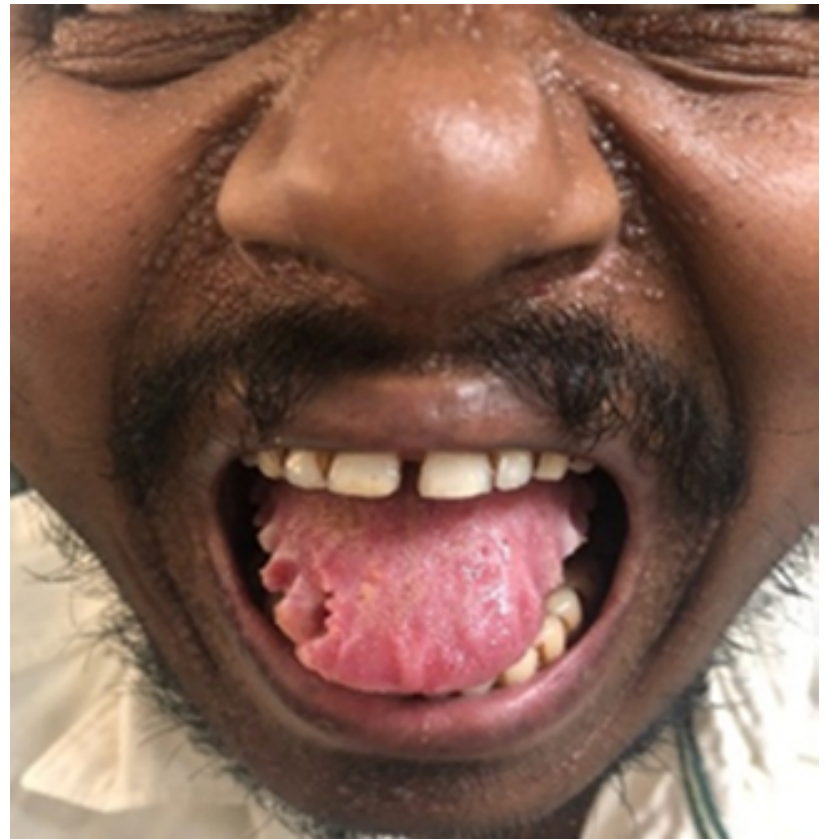

Figure 2. Macroglossia with teeth indentation marks on the sides of the tongue

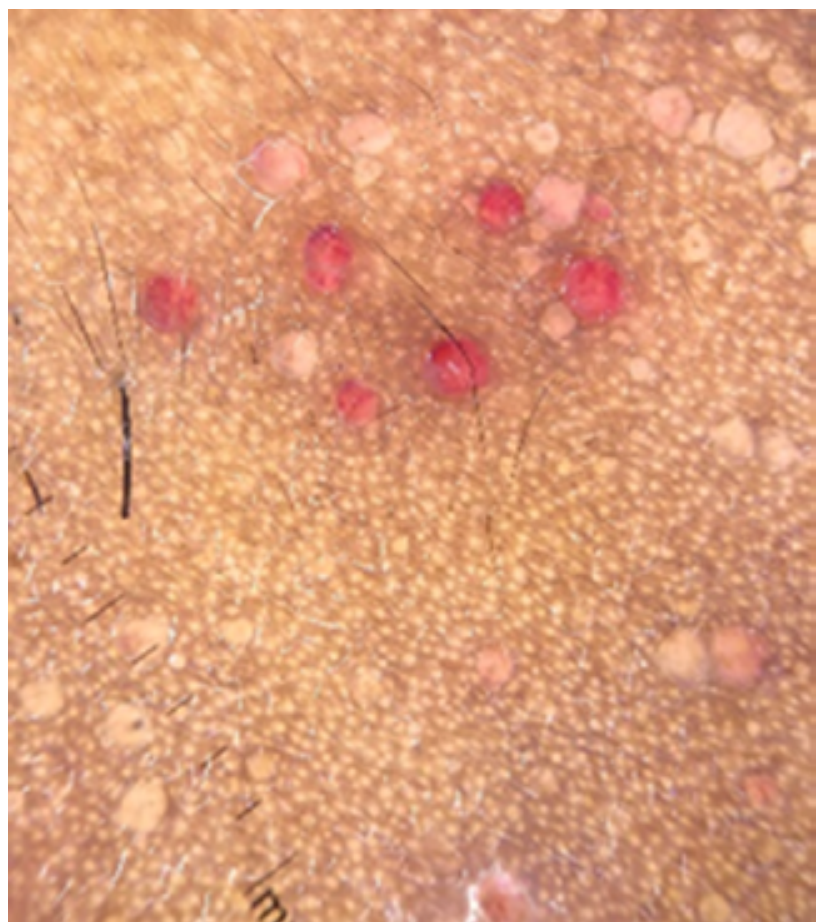

Figure 4. Red to pinkish background with vessels. (DermLite DL3, polarized view).

classically evident haemorrhagic papules of systemic amyloidosis. In literature, these glomerular vessels are commonly encountered in non-pigmented Bowen's disease and superficial basal cell carcinoma. Nevertheless, there are no reports of these vascular patterns in amyloidosis. In a report by $\mathrm{Hu}$ et al (2019), dermoscopy of facial papules in a case of systemic amyloidosis revealed a diffusely yellowish surface with pinpoint petechiae [1]. A high degree of suspicion and early 


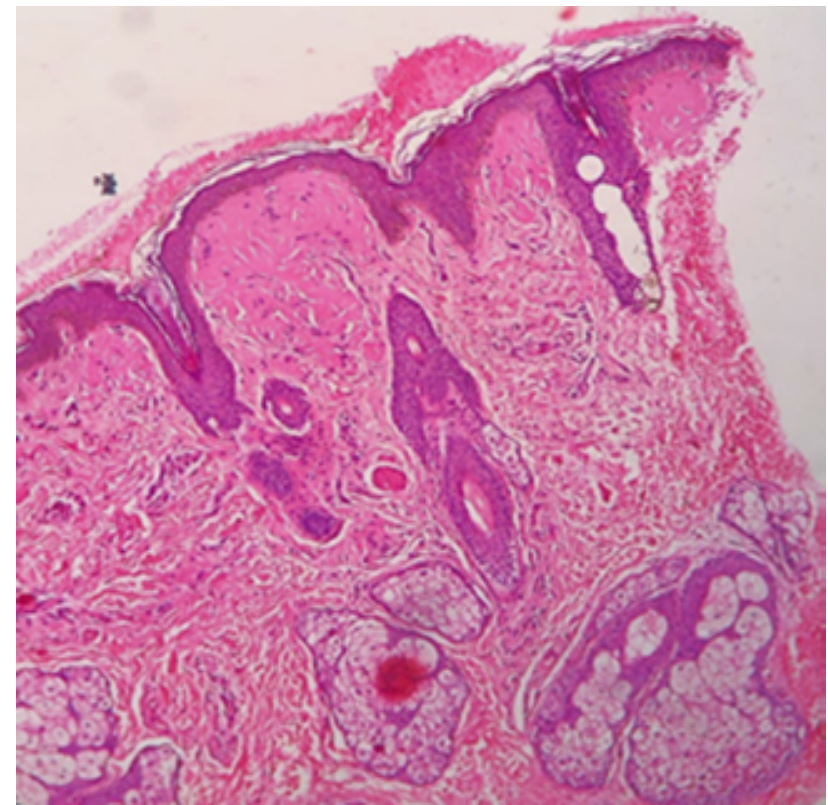

Figure 5. Histopathological features showing clumps of pale acellular eosinophilic material in the papillary dermis. (H\&E, X10).

dermoscopic evaluation can help prompting systemic amyloidosis' diagnosis with cutaneous involvement [2].

\section{Conclusion}

Glomeruloid vessels found in a yellowish background can represent a clinical feature of cutaneous lesions of primary systemic amyloidosis. These cutaneous findings can serve as an early dermoscopic sign to suspect cutaneous changes before the classic haemorrhagic appearance of systemic amyloidosis.

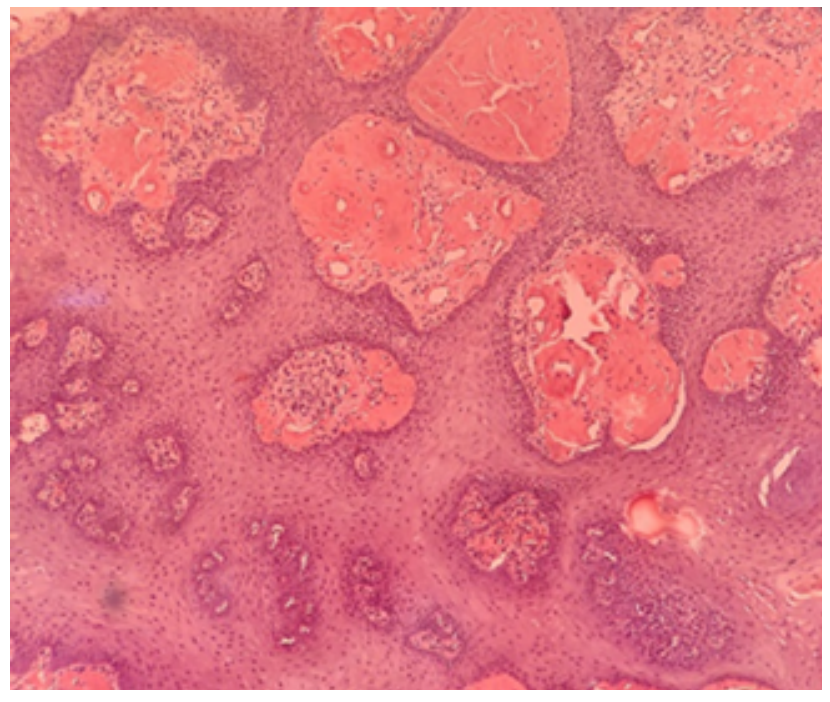

Figure 6. Congo red stain shows brick-red coloured amyloid deposits in the dermis and around blood vessels.

\section{References}

1. Stephen Chu-Sung Hu, Chi-Ling Lin, Hsin-Su Yu. Dermoscopic assessment of xerosis severity, pigmentation pattern and vascular morphology in subjects with physiological aging and photoaging. European Journal of Dermatology. 2019;29(3):274-280.

2. Ankad BS, Sakhare PS, Prabhu MH. Dermoscopy of non-melanocytic and pink tumors in brown skin: A descriptive study. Indian J Dermatopathol Diagn Dermatol.2017;4:41-51. DOI: 10.4103/ ijdpdd.ijdpdd_10_17 